OPEN ACCESS

Edited by:

Madhuri S. Salker,

University Hospital Tübingen,

Germany

Reviewed by: Sobuj Mia,

University of Alabama at Birmingham,

United States

Sangappa B. Chadchan,

Washington University in St. Louis,

United States

Lusine Aghajanova,

Stanford Health Care, United States

*Correspondence:

Mee-Sup Yoon

msyoon@gachon.ac.kr

Specialty section:

This article was submitted to

Molecular Medicine,

a section of the journal

Frontiers in Cell and Developmental

Biology

Received: 23 September 2020

Accepted: 12 November 2020

Published: 30 November 2020

Citation:

Khaliq SA, Baek M-O, Cho H-J,

Chon SJ and Yoon M-S (2020)

C-Peptide Inhibits Decidualization in Human Endometrial Stromal Cells via GSK3 $\beta-P P 1$.

Front. Cell Dev. Biol. 8:609551. doi: 10.3389/fcell.2020.609551

\section{C-Peptide Inhibits Decidualization in Human Endometrial Stromal Cells via GSK3 $\beta$-PP1}

\author{
Sana Abdul Khaliq ${ }^{1,2,3}$, Mi-Ock Baek ${ }^{1,2,3}$, Hye-Jeong Cho ${ }^{2}$, Seung Joo Chon ${ }^{4}$ and \\ Mee-Sup Yoon ${ }^{1,2,3 *}$
}

\begin{abstract}
${ }^{1}$ Department of Molecular Medicine, School of Medicine, Gachon University, Incheon, South Korea, ${ }^{2}$ Lee Gil Ya Cancer and Diabetes Institute, Gachon University, Incheon, South Korea, ${ }^{3}$ Department of Health Sciences and Technology, GAlHST, Gachon University, Incheon, South Korea, ${ }^{4}$ Department of Obstetrics and Gynecology, Gachon University Gil Medical Center, College of Medicine, Gachon University, Incheon, South Korea
\end{abstract}

Decidualization refers to the functional differentiation of endometrial stromal cells and plays a significant role in embryo implantation and pregnancy. C-peptide is excreted in equimolar concentrations as that of insulin during the metabolism of proinsulin in pancreatic beta-cells. High levels of C-peptide are correlated with hyperinsulinemia and polycystic ovarian syndrome, which show a defect in decidualization. However, the role of C-peptide in decidualization has not yet been studied. Here, we identified C-peptide as an endogenous antideciduogenic factor. This inhibitory function was confirmed by the reduced expression of decidual markers, including prolactin, insulin-like growth factor-binding protein-1, and Forkhead box protein 01 as well as by the fibroblastic morphological change in the presence of C-peptide. C-peptide also enhanced cellular senescence and decreased the proportion of apoptotic cells during decidualization. In addition, C-peptide potentiated the inhibitory effects of both insulin and palmitic acid in an AKT- and autophagy-independent manner, respectively. Furthermore, C-peptide augmented protein phosphatase 1 (PP1) activity, leading to a reduction in the inhibitory phosphorylation of glycogen synthase kinase (GSK)3 $\beta$, which resulted in enhanced cellular senescence and decreased apoptosis during decidualization. Taken together, our findings suggest that C-peptide is an antideciduogenic factor acting via the regulation between PP1 and GSK3 $\beta$ in patients with hyperinsulinemia.

Keywords: C-peptide, GSK3 $\beta$, PP1, decidualization, senescence, apoptosis

\section{INTRODUCTION}

The human proinsulin connecting peptide (C-peptide) is composed of 31 amino acids, which are cleaved from proinsulin during proteolytic processing (Bhatt et al., 2014; Leno-Duran et al., 2014). C-peptide links and stabilizes the A- and B- chains of insulin molecules, resulting in its proper folding and interchain disulfide bond formation. C-peptide and insulin are secreted in

Abbreviations: 8-Br-cAMP, 8-bromo adenosine $3^{\prime} 5^{\prime}$-cyclic adenosine monophosphate; Deci, decidualization; FOXO1, Forkhead box protein; IGFBP1, insulin-like growth factor binding protein 1; LiCl, Lithium chloride; I2, protein phosphatase1 inhibitor 2; OA, Okadaic acid; PA, palmitic acid; PP, protein phosphatase; PRL, prolactin; shPP1C, shRNA for PPP1Ca; shScram, shRNA for scramble. 
equimolar concentrations from the pancreatic $\beta$-cells (Beischer et al., 1976; Wahren et al., 2000), with C-peptide largely viewed as an inert marker for insulin production with negligible metabolism in the liver (Hills and Brunskill, 2009). However, recent studies have revealed several important physiological and protective functions of C-peptide in diabetic complications, suggesting that this byproduct may play a hormone-like role in diverse aspects of cellular signaling.

It has been suggested that C-peptide exerts its effect by binding to Gai-coupled G-protein-coupled receptor (GPCR) on the cellular surface, which is supported by a previous study that demonstrated high-affinity interactions between a fluorophorelabeled C-peptide and human cell membranes (Rigler et al., 1999). C-peptide has been reported to activate phospholipase C (PLC) - $\mathrm{Ca}^{2+}$-dependent signaling pathways, thereby increasing the activity of both $\mathrm{Na}^{+}-\mathrm{K}^{+}$-ATPase and endothelial nitric oxide synthase. It has also been shown to stimulate mitogen-activated protein kinase (MAPK), leading to the activation of $\mathrm{Na}^{+}-\mathrm{K}^{+}$ATPase and numerous transcription factors, including cAMP response element-binding protein (CREB), nuclear factor kappa beta $(\mathrm{NF}-\kappa \mathrm{B})$, and activating transcription factor 1 (ATF1). These functions may play some protective roles in diabetic vascular dysfunction, micro- and/or macro-vascular damage, and diabetic neuropathy (Wahren et al., 2000). In addition, C-peptide induces cyclin D1 expression, promoting the critical transition of cell proliferation from G1- to S-phase via the activation of retinoblastoma protein phosphorylation in smooth muscles of both rats and humans (Walcher et al., 2006). These results suggest that $\mathrm{C}$-peptide plays several functional roles in diverse tissues and biological contexts, in addition to its role in diabetes. However, the potential effects of C-peptide signaling on endometrium differentiation during embryo implantation and pregnancy maintenance have not yet been investigated.

Decidualization is the process of transformation of endometrial fibroblasts to secretory round-shaped decidual cells during the menstrual cycle and pregnancy (Gellersen and Brosens, 2014). Elevated progesterone levels during the mid-secretory phase of the menstrual cycle induce a decidua-like morphological change in the stromal cells that surround the spiral arteries in the endometrium (Okada et al., 2018). During this process, the decidual stromal cells provide the key nutrients to support placental development and ultimately embryo implantation (Dunn et al., 2003). The extended cytoplasm of the decidual stromal cells contains glycogen and lipid droplets and an increased number of intracellular phagosomes and lysosomes, possibly contributing to the intense remodeling of the extracellular matrix (ECM) and the release of diverse cytokines and signaling molecules (Gellersen and Brosens, 2014). In addition, these cells express diverse signal coordinators, which serve as decidual markers, including prolactin (PRL), insulin-like growth factor-binding protein-1 (IGFBP1), Forkhead box protein $\mathrm{O} 1$ (FOXO1), and the NODAL-signaling pathway inhibitor left-right determination factor 2 (LEFTY2).

A high level of C-peptide is closely accompanied by hyperinsulinemia and insulin resistance (Hills and Brunskill, 2009), which have been linked to several endocrine conditions and pregnancy complications. Patients with polycystic ovarian syndrome (PCOS), characterized by hyperandrogenism and hyperinsulinemia, have a high risk of recurrent pregnancy loss and miscarriage (Chakraborty et al., 2013). Treatment of patients with PCOS with metformin reduces the occurrence of early pregnancy loss (Nawaz and Rizvi, 2010), suggesting that insulin resistance or hyperinsulinemia may play a significant role in early pregnancy loss in PCOS patients. Hence, we hypothesize that C-peptide under hyperinsulinemia affects decidualization and subsequently maintaining pregnancy. Here, we examined for the first time whether $\mathrm{C}$-peptide played a role in decidualization and further investigated the mechanistic regulation involved. Our findings reveal a novel role for $\mathrm{C}$-peptide in the endometrium and provide an explanation for the high risk of recurrent pregnancy loss in patients with hyperinsulinemia.

\section{MATERIALS AND METHODS}

\section{Antibodies and Other Reagents}

The primary antibodies used in this study are listed in Supplementary Table 1 . The secondary antibodies were obtained from Jackson Immuno Research Laboratories Inc. (West Grove, PA, United States) (anti-mouse \#115-035-003; anti-rabbit\# 211002-171). The C-peptide was synthesized by Peptrone (Daejon, South Korea). A palmitic acid (PA) solution was prepared using $20 \mathrm{mM}$ PA in $150 \mathrm{mM} \mathrm{NaCl}$ with $5 \%$ bovine serum albumin. Okadaic acid (OA) was dissolved in DMSO. A list of the reagents used in this study is provided in Supplementary Table 2.

\section{Isolation and Culture of Human eSCs}

Human endometrial stromal cells (human eSCs) were isolated from the human endometrium acquired through hysterectomies of 25 premenopausal women aged 46-52 years. The participants showed no sign of glucose metabolism irregularities, diabetes, or PCOS and underwent surgery for non-endometrial abnormalities at the Gil Hospital. The information of participants is presented in Supplementary Table 3. All experiments were performed in compliance with the relevant guidelines and regulations of Gachon University (GAIRB2018-301). Written informed consent was obtained from all participants. Isolation of eSCs was performed following a previously reported procedure (Yoon et al., 2007). After isolation, the cells were used under 4 passages. Human eSCs were grown in Dulbecco's modified Eagle's medium (DMEM) containing $1 \mathrm{~g} / \mathrm{L}$ glucose and supplemented with $10 \%$ fetal bovine serum (FBS) at $37^{\circ} \mathrm{C}$ with $5 \% \quad \mathrm{CO}_{2}$ and were detached from the plate using $0.05 \%$ trypsin-EDTA (Welgene, Gyeongsangbuk-do, South Korea). In vitro decidualization was induced by plating the cells and growing them to $100 \%$ confluency by treating them with DMEM containing 10\% FBS, $1 \%$ penicillin/streptomycin $(10,000 \mathrm{U} / \mathrm{mL})$, and $0.5 \mathrm{mM}$ 8-bromo adenosine $3^{\prime} 5^{\prime}$-cyclic adenosine monophosphate (8Br-cAMP). Fresh medium was provided on alternate days (Baek et al., 2018).

\section{Cell Lysis and Western Blot Analysis}

Human eSCs were washed once with ice-cold phosphate-buffered saline (PBS), scraped, and lysed with 1X lysis buffer (Cell 


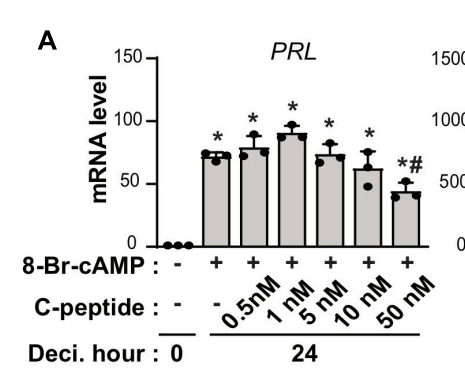

B

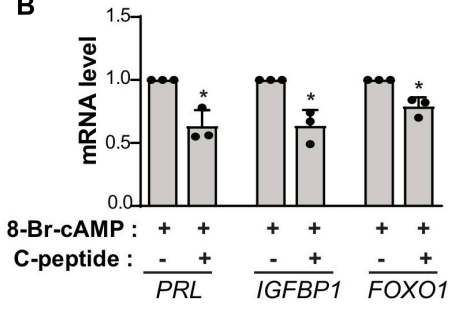

D
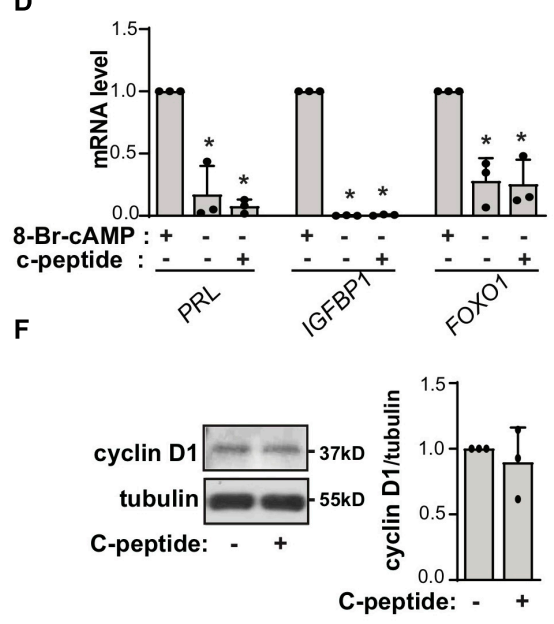

E

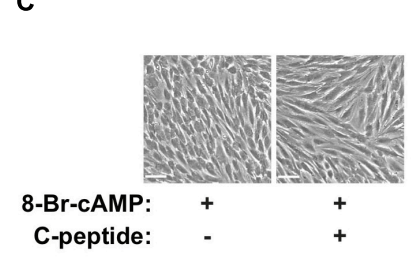

FOXO1

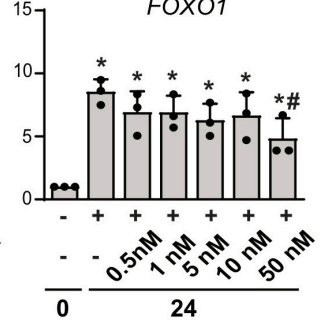

24

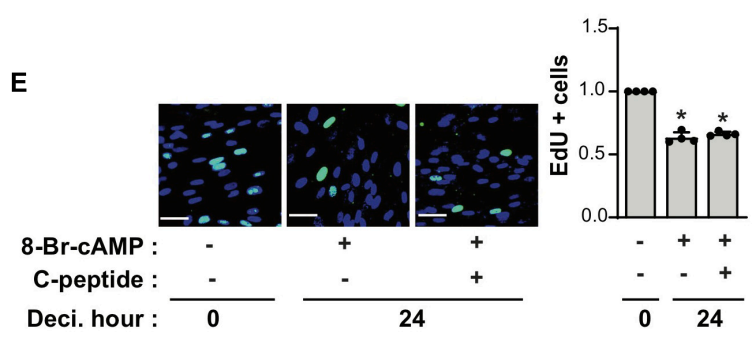

G

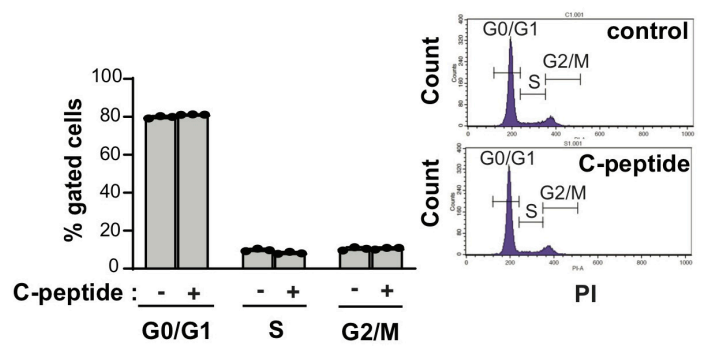

FIGURE 1 | C-peptide decreases decidualization in human endometrial stromal cells. (A) Human eSCs were induced to decidualize with 0.5 mM 8-Br-cAMP in the presence of an indicated concentration of C-peptide for $24 \mathrm{~h}$. The cells were then lysed and subjected to qRT-PCR ( $n=3$ ). (B) qRT-PCR results for human eSCs from three different people $(n=3)$ treated with $0.5 \mathrm{mM} 8$-Br-cAMP with or without $50 \mathrm{nM}$ C-peptide for $24 \mathrm{~h}$. (C) Cells were induced to differentiate in the presence of 8-Br-cAMP with or without 50 nM C-peptide for 4 days and photographed using Nikon Eclipse Ti2 microscope (X4). Scale bar = 100 $\mu \mathrm{m}$ ( $n=3$ ). (D) Human eSCs were induced to differentiate in the presence of $0.5 \mathrm{mM} 8$-Br-cAMP for 2 days; subsequently, the 8-Br-cAMP was withdrawn, and the cells were incubated for further 2 days. The cells were lysed and analyzed using qRT-PCR $(n=3)$. (E) Cells were induced to decidualize using $0.5 \mathrm{mM} 8$-Br-cAMP in the presence or absence of 50 $\mathrm{nM}$ C-peptide for $24 \mathrm{~h}$ and stained for detecting EdU incorporation. The cells were photographed using Olympus CKX53 microscope (X20). Scale bar = 50 $\mu \mathrm{m}$ $(n=3)$. (F) Cells were treated with $50 \mathrm{nM} \mathrm{C}$-peptide for $24 \mathrm{~h}$ and then subjected to western blot analysis $(n=3)$. (G) Cells were treated as in (E), stained with PI, and analyzed using flow cytometry $(n=3) .{ }^{\star} P<0.05$, ${ }^{\star \star} P<0.01$ versus an undifferentiated control; ${ }^{\#} P<0.05$ vs. a differentiated control. Human eSCs from two to three different people were used.

Signaling Technology). The supernatant was collected after microcentrifugation at $13,000 \times g$ for $10 \mathrm{~min}$ and then boiled for $5 \mathrm{~min}$ in sodium dodecyl sulfate (SDS) sample buffer (Baek et al., 2019). Proteins were then subjected to SDS-polyacrylamide gel electrophoresis and transferred to polyvinylidene fluoride membranes (Millipore, Billerica, MA, United States). These membranes were blocked with 5\% skimmed milk phosphate buffered saline with $0.1 \%$ Tween 20 (PBST) for $30 \mathrm{~min}$ and then incubated overnight with the primary antibodies in 5\% skimmed milk in PBST. Membranes were then washed and incubated with horseradish peroxidase (HRP)-conjugated secondary antibodies for $30 \mathrm{~min}$ at room temperature. Secondary antibodies were detected using Immobilon Western Chemiluminescent HRP Substrate (Millipore). The experiment was performed according to the manufacturer's instructions.

\section{Quantitative Reverse Transcription PCR}

Total RNA was extracted from the human eSCs using TRIzol reagent (Thermo Fisher Scientific, Waltham, MA, United States), and $2 \mu \mathrm{g}$ of this RNA was used to synthesize 
A

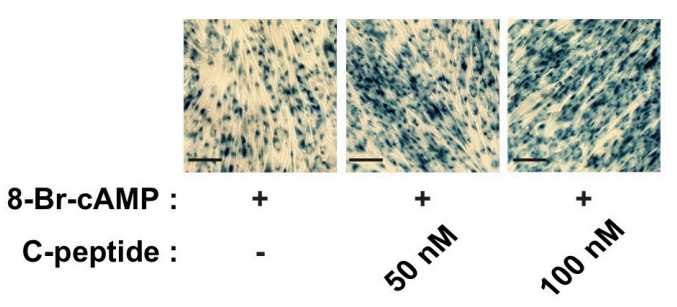

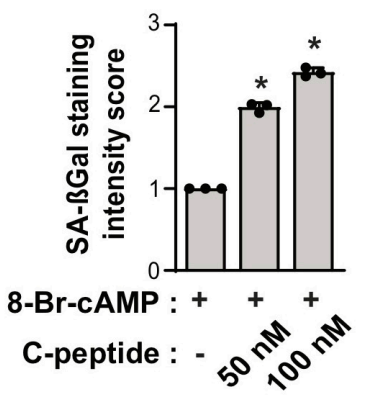

B

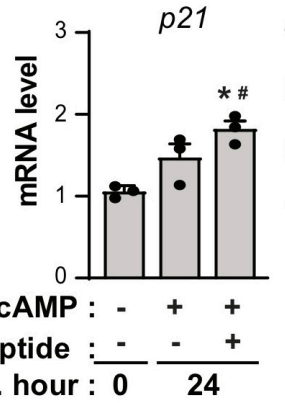

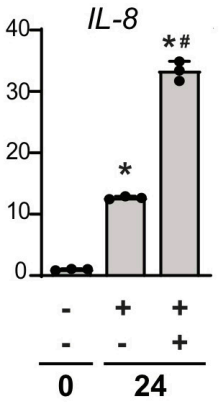

C

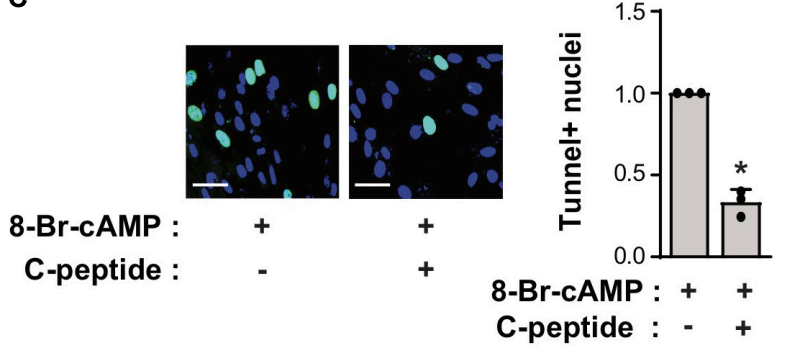

FIGURE 2 | C-peptide increases cellular senescence but decreases apoptosis. (A) Human eSCs were induced to differentiate in the presence of 0.5 mM 8 -Br-cAMP with or without $50 \mathrm{nM}$ or $100 \mathrm{nM} \mathrm{C-peptide} \mathrm{for} 4$ days, and cellular senescence was measured using a senescence- $\beta$-galactosidase (SA- $\beta$ G) assay. The cells were photographed by Zeiss imager Z1 microscope (X5). The staining intensity of the positive cells was scored as 0 (staining absent); 1 (partial cytoplasmic staining); or 2 (total cytoplasmic staining). Scale bar $=100 \mu \mathrm{m}(n=3)$. (B) The cells were decidualized with $0.5 \mathrm{mM} 8$-Br-cAMP in the presence or absence of $50 \mathrm{nM}$ C-peptide for $24 \mathrm{~h}$. These cells were then lysed and subjected to qRT-PCR analysis $(n=3)$. (C) The cells were induced to differentiate in the presence of $0.5 \mathrm{mM} 8$-Br-cAMP with or without C-peptide for 2 days and then subjected to the TUNEL assay. The cells were photographed using Olympus CKX53 microscope (X20). Scale bar $=50 \mu \mathrm{m}$ $(n=3) .{ }^{\star} P<0.05,{ }^{\star \star} P<0.01$ vs. an undifferentiated control; ${ }^{\#} P<0.05$ versus a differentiated control. Human eSCs from two to three different people were used.

cDNA using the TOPscript ${ }^{\mathrm{TM}}$ RT DryMIX kit (dT18 plus) following the manufacturer's instructions (Enzynomics, Daejeon, South Korea). Quantitative reverse transcription PCR (qRT-PCR) was conducted using TOPreal ${ }^{\mathrm{TM}}$ qPCR $2 \mathrm{X}$ PreMIX (SYBR Green with high ROX) (Enzynomics) and a CFX384 C1000 Thermal Cycler (Bio-Rad, Hercules, CA, United States). Human L19 was used to normalize $I L-8$ expression, and glyceraldehyde 3phosphate dehydrogenase (GAPDH) was used to normalize the expression of the other genes. The primers used for qRT-PCR, such as for FOXO1, GAPDH, IGFBP1, PRL (Baek et al., 2018), L19 (Francis et al., 2006), p16 (Zhang et al., 2017), and p53 (Zhou et al., 2017) have been previously reported. Primers for IL8 and p21 are listed in Supplementary Table 4.

\section{Cell Proliferation and Viability}

The proliferation of human eSCs was evaluated using a cell counting kit (CCK)-8 (Dojindo Laboratories Kumamoto, Japan) following the manufacturer's instructions. In addition, 5-ethynyl2 -deoxyuridine (EdU) labeling was performed as previously reported (Son et al., 2019). Briefly, the cells were pulsed with Edu $(10 \mu \mathrm{M})$ for $2 \mathrm{~h}$ before harvesting. Then, the cells were fixed in $3.7 \%$ formaldehyde for $15 \mathrm{~min}$ and labeled with an Edu mixture containing ascorbic acid, $\mathrm{CuSO}_{4}$, and fluorescein (FAM) azide at final concentrations of 500,100, and $10 \mathrm{mM}$, respectively, for $30 \mathrm{~min}$ at room temperature in the dark. After incubation with $4^{\prime}, 6^{\prime}$-diamidino-2-phenylindole (DAPI) $(1: 5,000)$ for $20 \mathrm{~min}$, the cells were observed under a fluorescent microscope (Olympus CKX3-Houn Microscope; Olympus, Tokyo, Japan) equipped with a 20X objective. The fluorescent images were captured using Retiga R6 (Qimaging, Surrey, BC, Canada). EdU-labeled cells were counted using an Image J cell counter.

\section{Analysis of Apoptotic Cells}

Apoptosis was examined using a TUNEL assay kit according to the manufacturer's protocol (Promega, Madison, WI, United States).

\section{Cell Cycle Analysis}

The cells were collected by centrifugation at $1000 \times g$ for $5 \mathrm{~min}$ at a concentration of $3 \times 10^{5}$ cells per tube and washed twice with PBS. The cell pellets were suspended in $70 \%$ ethanol $(1 \mathrm{~mL})$ at 4 ${ }^{\circ} \mathrm{C}$ for $1 \mathrm{~h}$ and washed again once with PBS. They were then resuspended in $0.5 \mathrm{~mL}$ of propidium iodide (PI, $50 \mathrm{mg} / \mathrm{L}$ ) and $1.5 \%$ RNase A $(7 \mathrm{mg} / \mathrm{mL})$ for $30 \mathrm{~min}$ at $37^{\circ} \mathrm{C}$ in the dark, and analyzed using flow cytometry (BD FACS Calibur; BD Biosciences, San Jose, CA, United States).

\section{$\beta$-Galactosidase Staining}

The cells were stained with senescence-associated $\beta$-galactosidase (senescence-associated $\beta$-galactosidase staining kit, Cell Signaling 
A

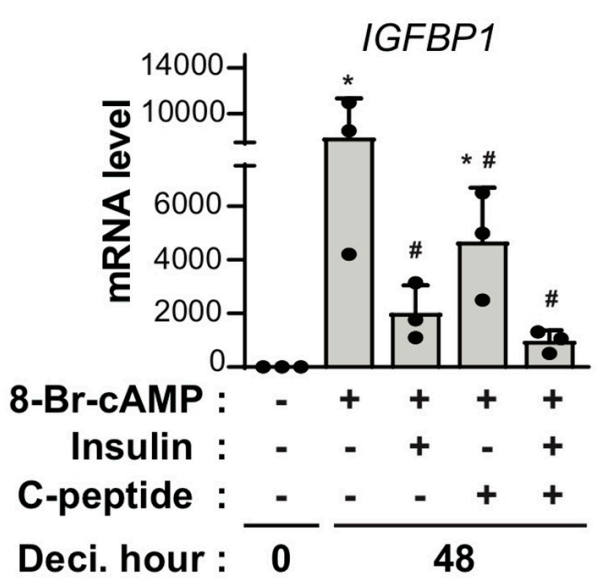

B

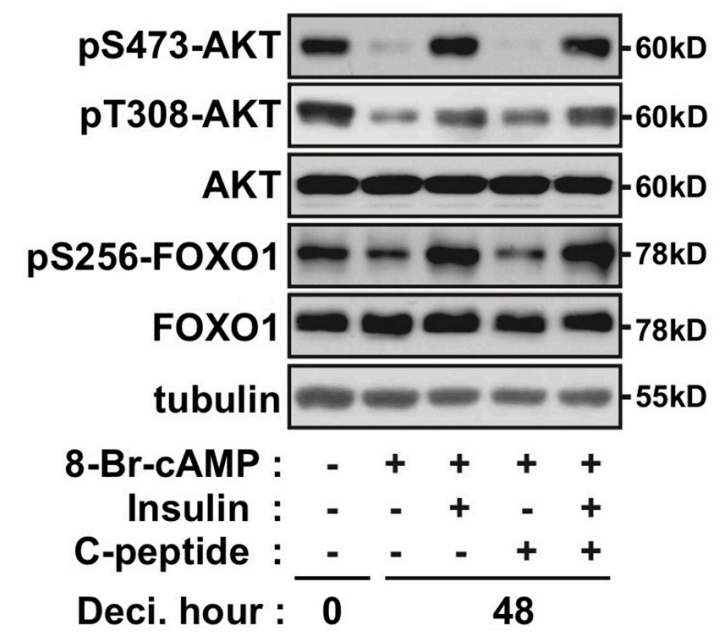

C

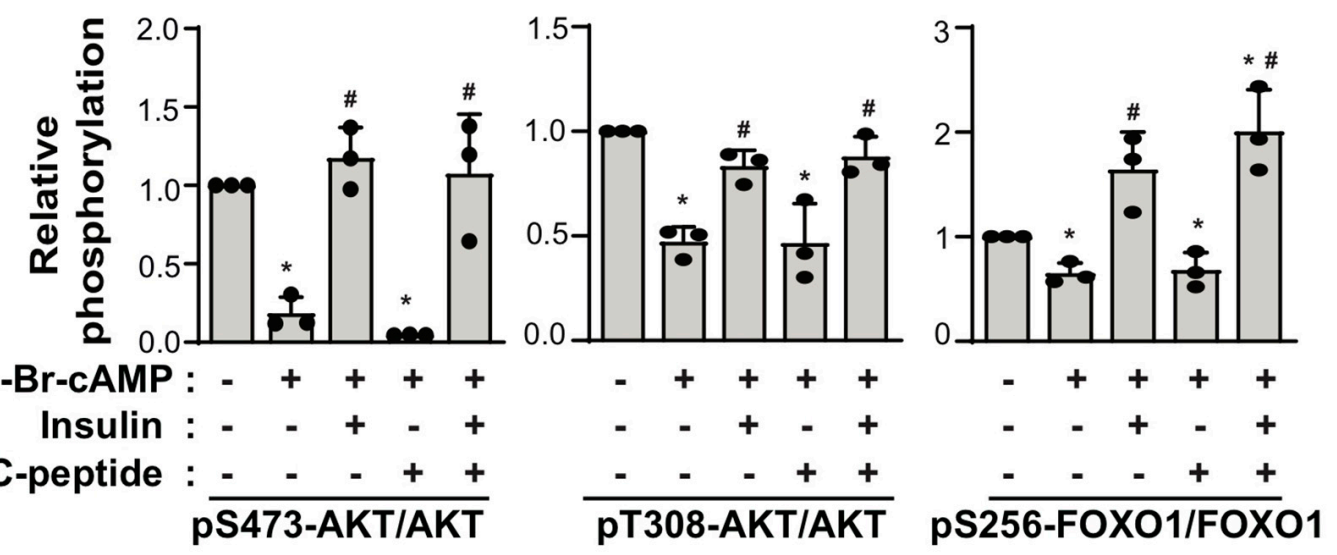

FIGURE 3 | C-peptide inhibits decidualization independent of insulin-induced inhibitory mechanism. (A) Human eSCs were induced to differentiate using $0.5 \mathrm{mM}$ 8-Br-CAMP in the presence of $100 \mathrm{nM}$ insulin, $50 \mathrm{nM}$ C-peptide, or cotreatment with insulin and C-peptide for $48 \mathrm{~h}$, followed by cell lysis and qRT-PCR analysis of the RNA samples $(n=3)$. (B) The cells were treated as described in (A), followed by lysis, and the lysates were subjected to western blotting $(n=3)$. (C) The relative intensities of the bands were quantified using ImageJ analysis software $(n=3)$. Data represent pSer473-AKT and pThr308-AKT as compared to AKT and pSer256-FOXO1 as compared to FOXO1. ${ }^{*} P<0.05$ versus an undifferentiated control; ${ }^{*} P<0.05$ vs. a differentiated control. Human eSCs from two to three different people were used.

Technology) according to the manufacturer's instructions. The cells were photographed using an Imager Z1 (Zeiss) microscope equipped with a $5 \mathrm{X}$ objective (Oberkochen, Land BadenWürttemberg, Germany). Senescent cells were detected as bluestained, and the staining intensity of positive cells was scored as 0 (staining absent), 1 (partial cytoplasmic staining), and 2 (total cytoplasmic staining). A total of 300 cells were counted in three random fields of view for each sample.

\section{Protein Phosphatase Assay}

Protein phosphatase activity was measured as previously reported (McAvoy and Nairn, 2010). Briefly, the cells were lysed using passive lysis buffer (Promega) and reacted with p-nitrophenylphosphate for $45 \mathrm{~min}$ in a colorimetric assay buffer
(20 mM Tris pH 7.5, $5 \mathrm{mM} \mathrm{MgCl}, 1 \mathrm{mM}$ ethylene glycol-bis ( $\beta$-aminoethyl ether)- $\mathrm{N}, \mathrm{N}^{\prime}, \mathrm{N}^{\prime}, \mathrm{N}$-tetraacetic acid (EGTA), $0.02 \%$ $\beta$-mercaptoethanol, and $0.1 \mathrm{mg} / \mathrm{mL}$ bovine serum albumin). The absorbance was measured at $405 \mathrm{~nm}$. The lysate containing the phosphatase inhibitor was used as a blank.

\section{Lentivirus-Mediated Short Hairpin RNA and Transfection}

Protein phosphatase catalytic subunit a (PPP1Ca) shRNAs were obtained from Sigma-Aldrich in the pLKO.1-puro vector (MISSION shRNA). Clone IDs were PP1C-1, TRCN0000002452, PP1C-2, and TRC0000002455, and the lentivirus packaging and testing were performed as previously described (Baek et al., 2018). 

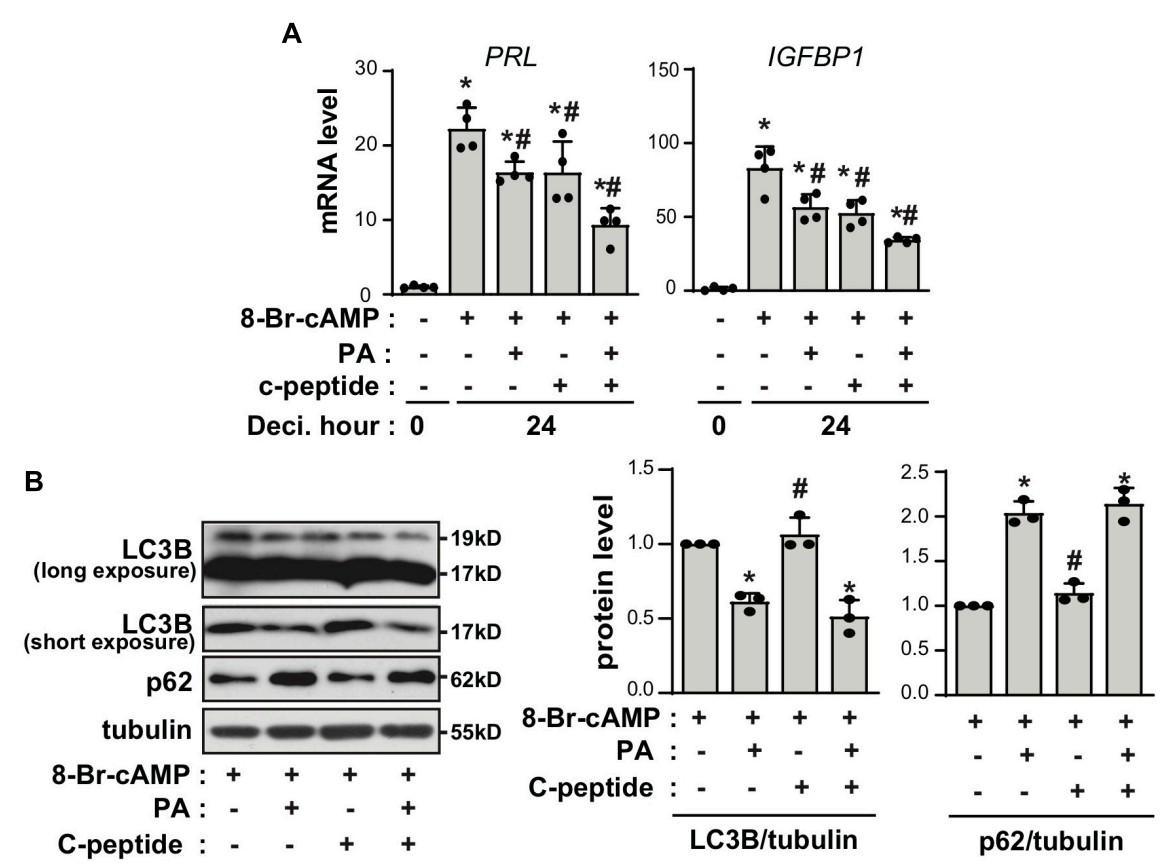

FIGURE 4 | C-peptide potentiates the inhibitory effect of palmitic acid on decidualization through autophagy-independent mechanism. (A) Human eSCs were treated with $0.5 \mathrm{mM} 8-\mathrm{Br}-\mathrm{cAMP}$ in the presence or absence of $100 \mu \mathrm{M}$ palmitic acid and $50 \mathrm{nM}$ C-peptide for $24 \mathrm{~h}$ as indicated. The cells were lysed and subjected to qRT-PCR analysis $(n=3)$. ${ }^{*} P<0.05$ vs. an undifferentiated control; ${ }^{*} P<0.05$ vs. a differentiated control. (B) The cells were treated as described in (A), lysed, and the lysates were subjected to western blotting. The relative intensities of the bands were quantified using ImageJ analysis software $(n=3)$. Data represent LC3B as compared to tubulin and $\mathrm{p} 62$ as compared to tubulin. ${ }^{*} P<0.05$ vs. a 8-Br-cAMP-treated group; ${ }^{\#} P<0.05$ vs. a PA and 8 -Br-cAMP-treated group. Human eSCs from two to three different people were used.

\section{Statistical Analysis}

All quantitative data are represented as the mean \pm standard deviation (SD) of at least three independent experiments. All data points are shown as dots in all quantified graphs. Means were calculated from the results of 3 to 6 independent experiments for all figures. The exact sample size for each experiment is described in the figure legends. Where necessary, the statistical significance of the data was determined using a two-tailed paired Student's $t$-test using Excel. The specific types of tests and the $P$-values, when applicable, are indicated in the figure legends. $P$-values $<0.05$ were considered statistically significant.

\section{RESULTS}

\section{C-Peptide Decreases Decidualization in Human Endometrial Stromal Cells}

To assess the effect of C-peptide on decidualization in human eSCs, the cells were treated with $0.5 \mathrm{mM} 8$-Br-cAMP in the presence or absence of C-peptide. The cells were differentiated in the presence of 8-Br-cAMP as shown by increased mRNA expression of decidualization markers, including PRL, IGFBP1, and FOXO1 (Figure 1A). Notably, treatment with C-peptide significantly decreased the mRNA expression of $P R L, I G F B P 1$, and FOXO1 in a concentration-dependent manner (Figure 1A).
The low concentration of C-peptide $(1 \mathrm{nM})$ started to decrease PRL mRNA expression after induction of decidualization for 2 days (Supplementary Figure 1A), and inhibited for 3 or 6 daydecidualization (Supplementary Figures 1A,B). Primary eSCs from different individuals were differentiated using 8-Br-cAMP induction over a 2 day-period in the presence or absence of $50 \mathrm{nM}$ C-peptide, and the results of their differentiation confirmed the antideciduogenic effect of C-peptide (Figure 1B). In addition, human eSCs remained fibroblast-like in the presence of 8-BrcAMP and $50 \mathrm{nM}$ C-peptide for 4 days as observed under a microscope, whereas the cells treated with only 8 -Br-cAMP were enlarged and round (Figure 1C). The antideciduoginic effect in C-peptide and 8-Br-cAMP-co-treated cells for 4 days were proved by the decrease in mRNA expression of decidualization markers (Supplementary Figure 1C). When 8-Br-cAMP was withdrawn from the decidualized human eSCs, human eSCs underwent dedifferentiation and reverted to fibroblast-like cells with low levels of PRL and IGFBP1, as previously reported (Yoon et al., 2007; Figure 1D). This reversal in the presence of C-peptide was comparable to the observations made in the absence of C-peptide (Figure 1D; second bar vs. third bar), indicating that C-peptide did not facilitate the restoration of the growth status of human eSCs. In addition, C-peptide did not affect human eSCs exiting the cell cycle, as reflected by no changes in EdU-positive cell staining during c-AMP-induced decidualization (Figure 1E), along with no changes in cyclin D1 expression (Figure 1F), or in the G1, G2, and S phase ratios of PI-stained cells (Figure 1G). 
A

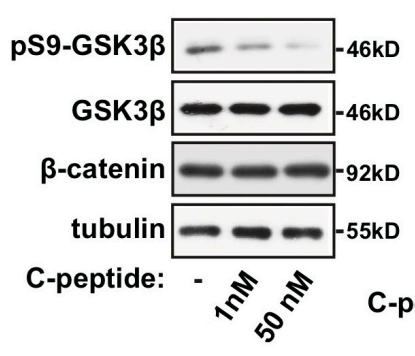

C

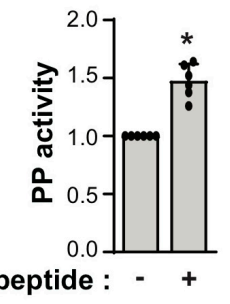

$\mathbf{F}$

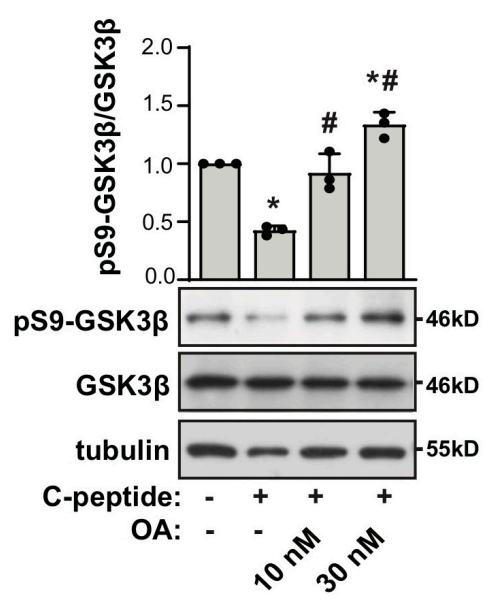

D

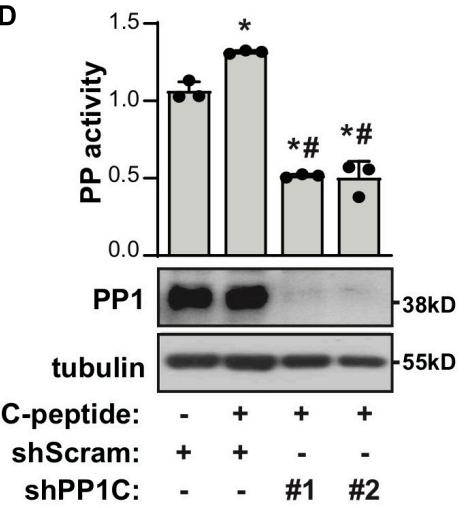

B

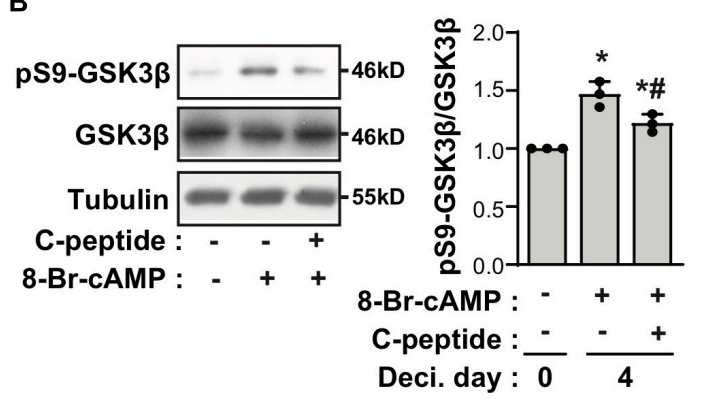

E

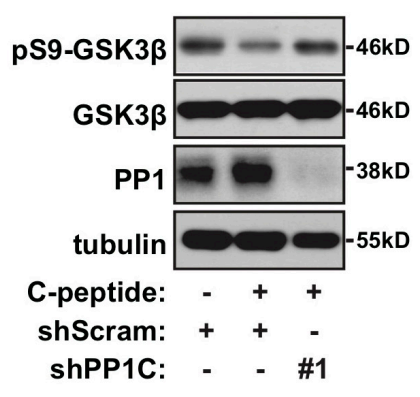

G

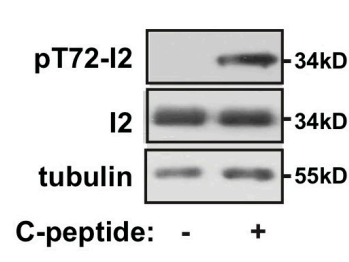

H

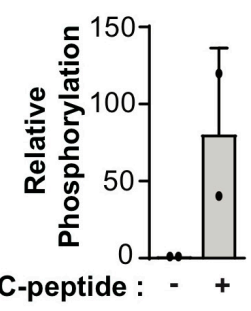

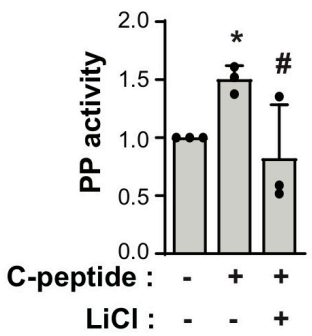

FIGURE 5 | C-peptide decreases the phosphorylation of GSK3 $\beta$ in PP1 activity-dependent manner. (A) Human eSCs were serum-starved for $18 \mathrm{~h}$ and treated with $1 \mathrm{nM}$ or $50 \mathrm{nM}$ C-peptide for $10 \mathrm{~min}$. The cells were lysed and subjected to western blotting $(n=3)$. (B) Cells were treated with $0.5 \mathrm{mM} 8$-Br-cAMP in the presence of $50 \mathrm{nM}$ C-peptide for 4 days. The cells were lysed and subjected to western blotting $(n=3)$. (C) Human eSCs were serum-starved for $18 \mathrm{~h}$ and treated with $50 \mathrm{nM}$ C-peptide for $10 \mathrm{~min}$. The cells were lysed and subjected to a protein phosphatase (PP) assay using p-nitrophenyl phosphate and evaluated at 405 nm ( $n=6)$. (D,E) Human eSCs were transduced with shScram and shPP1C and selected using $2 \mu \mathrm{M}$ puromycin for 5 days. Cells were serum-starved and treated with $50 \mathrm{nM}$

C-peptide for 10 min. (D) PP activity was evaluated as same as (C). (D,E) The lysates were analyzed by western blotting. (F) After cells were serum-starved for $18 \mathrm{~h}$ and pretreated with $10 \mathrm{nM}$ or $30 \mathrm{nM} \mathrm{OA}$ for $1 \mathrm{~h}$, cells were treated with $50 \mathrm{nM}$ C-peptide for 10 min. The lysates were subjected to western blot analysis. (G) Cells were treated as $\mathbf{( C )}$, lysed and subjected to western blotting $(n=3)$. $(\mathbf{H})$ The cells were serum-starved for $18 \mathrm{~h}$, pretreated with $40 \mu \mathrm{M}$ LiCl for $1 \mathrm{~h}$, treated with 50 nM C-peptide for 10 min, and subjected to PP activity assay $(n=3)$. ${ }^{*} P<0.05$ vs. control; ${ }^{*} P<0.05$ vs. a differentiated control (B) or C-peptide-treated cells $\mathbf{( D , F , H ) . ~ T h e ~ r e l a t i v e ~ i n t e n s i t i e s ~ o f ~ t h e ~ b a n d s ~ w e r e ~ q u a n t i f i e d ~ u s i n g ~ I m a g e J ~ a n a l y s i s ~ s o f t w a r e . ~ D a t a ~ r e p r e s e n t ~ p S e r 9 - G S K 3 \beta ~ a s ~ c o m p a r e d ~ t o ~ G S K 3 ~} \beta$ (A,B,F), $\beta$-catenin to tubulin (A), and pThr72-I2 to I2 (G). Human eSCs from two to four different people were used.

\section{C-Peptide Increases Cellular Senescence and Decreases Apoptosis During Decidualization}

Senescence-associated $\beta$-galactosidase $(\mathrm{SA} \beta \mathrm{G})^{+}$cell numbers increase during decidualization, whereas cellular senescence prevents the differentiation of endometrial mesenchymal stem cells in decidualized cultures (Brighton et al., 2017). When cells were decidualized with 8 -Br-cAMP in the presence of $\mathrm{C}$-peptide, $\mathrm{SA} \beta \mathrm{G}^{+}$eSCs increased in a dose-dependent manner (Figure 2A). Although this marker for cellular senescence is expressed heterogeneously depending on both the cell type and the insult, the stimulus of senescence increases the expression of cell cycle arrest mediators such as p21 as well as secreted factors 


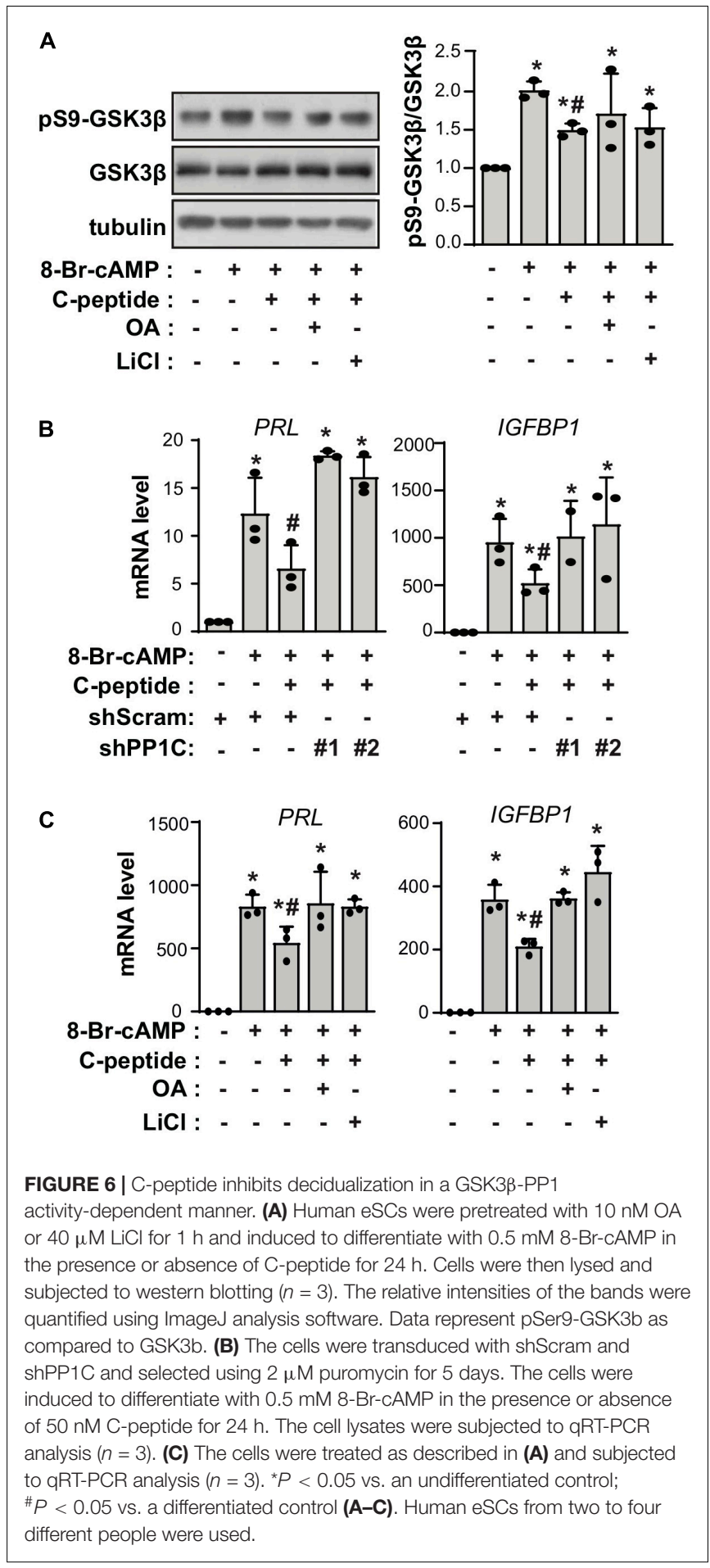

of senescence-associated secreted phenotypes (SASP) such as IL-8 (Deryabin et al., 2020). The mRNA levels of senescence markers $p 21$ and $I L-8$ increased significantly $24 \mathrm{~h}$ after treatment with 8-Br-cAMP and C-peptide (Figure 2B). In addition, apoptosis was decreased, as demonstrated by a decrease in the number of dead-end TUNEL-positive cells during 8-Br-cAMPinduced decidualization (Figure 2C). Apoptosis increases during c-AMP-induced decidualization (Leno-Duran et al., 2014) and senescence counteracts apoptosis in a p21-dependent manner (Munoz-Espin et al., 2013). Thus, these observations suggest that C-peptide leads to an increase in decidual senescence and a decrease in apoptosis, resulting in defective decidualization.

\section{C-Peptide Potentiates the Inhibitory Effect of Either Insulin or Palmitic Acid on Decidualization}

C-peptide is produced at equimolar concentrations to that of insulin in pancreatic $\beta$-cells during the enzymatic cleavage of proinsulin to insulin (Jones and Hattersley, 2013). Thus, we speculated whether the antideciduogenic effect of C-peptide was regulated by the same pathway as that of insulin. Insulin inhibits decidualization by decreasing the expression of IGFBP1, but not PRL, in a FOXO1-dependent manner (Ujvari et al., 2017). As shown in Figure 3A, treatment with insulin reduced the mRNA expression of IGFBP1, as previously reported (Ujvari et al., 2017). Notably, cotreatment with insulin and C-peptide further inhibited IGFBPI mRNA expression (Figure 3A), suggesting that $\mathrm{C}$-peptide has an additional inhibitory effect on IGFBP1 expression in addition to the antideciduogenic effects of insulin. In addition, the phosphorylation of AKT and FOXO1 increased in the presence of insulin during decidualization, as previously reported (Ujvari et al., 2017), whereas they remained unchanged following treatment with C-peptide (Figures 3B,C). Moreover, cotreatment with insulin and C-peptide did not potentiate the phosphorylation of AKT and FOXO1 (Figures 3B,C), indicating that C-peptide inhibited 8-Br-cAMP-induced decidualization independent of AKT/FOXO1 signaling. In addition, C-peptide levels are reportedly increased in obese women with hyperinsulinemia (Poniedziałek-Czajkowska et al., 2018). Palmitic acid (PA) is the most abundant unsaturated fatty acid in the current western diet and contributes to hyperlipidemia (Kien et al., 2014). PA has been reported to inhibit decidualization by decreasing autophagic flux (Rhee et al., 2016). Exposure to $100 \mu \mathrm{M}$ PA suppressed decidualization, as demonstrated by a decrease in mRNA expression of $P R L$ and IGFBP1, as previously reported (Rhee et al., 2016), and co-treatment with PA and C-peptide reduced PRL and IGFBP1 mRNA expression (Figure 4A). However, autophagic flux remained unchanged in the presence of C-peptide, whereas it was dampened in the presence of PA or the combination of C-peptide and PA (Figure 4B), suggesting that $\mathrm{C}$-peptide regulates decidualization via a mechanism different from autophagic flux.

\section{C-Peptide Decreases the Phosphorylation of GSK3 $\beta$ at Ser9 in a PP1-Dependent Manner}

To uncover the mechanism underlying the effect of C-peptide on decidualization, we evaluated the phosphorylation status of GSK3 $\beta$ in C-peptide-treated human eSCs. Inhibition of GSK3 $\beta$ attenuates apoptosis (Souder and Anderson, 2019), and GSK3 $\beta$ blockage is reported to be accompanied by a decrease in the level of SA $\beta G^{+}$cells (Zmijewski and Jope, 2004). The changes in GSK3 $\beta$ activity are facilitated by the inhibitory phosphorylation of Ser9 in the amino-terminal motif, which 

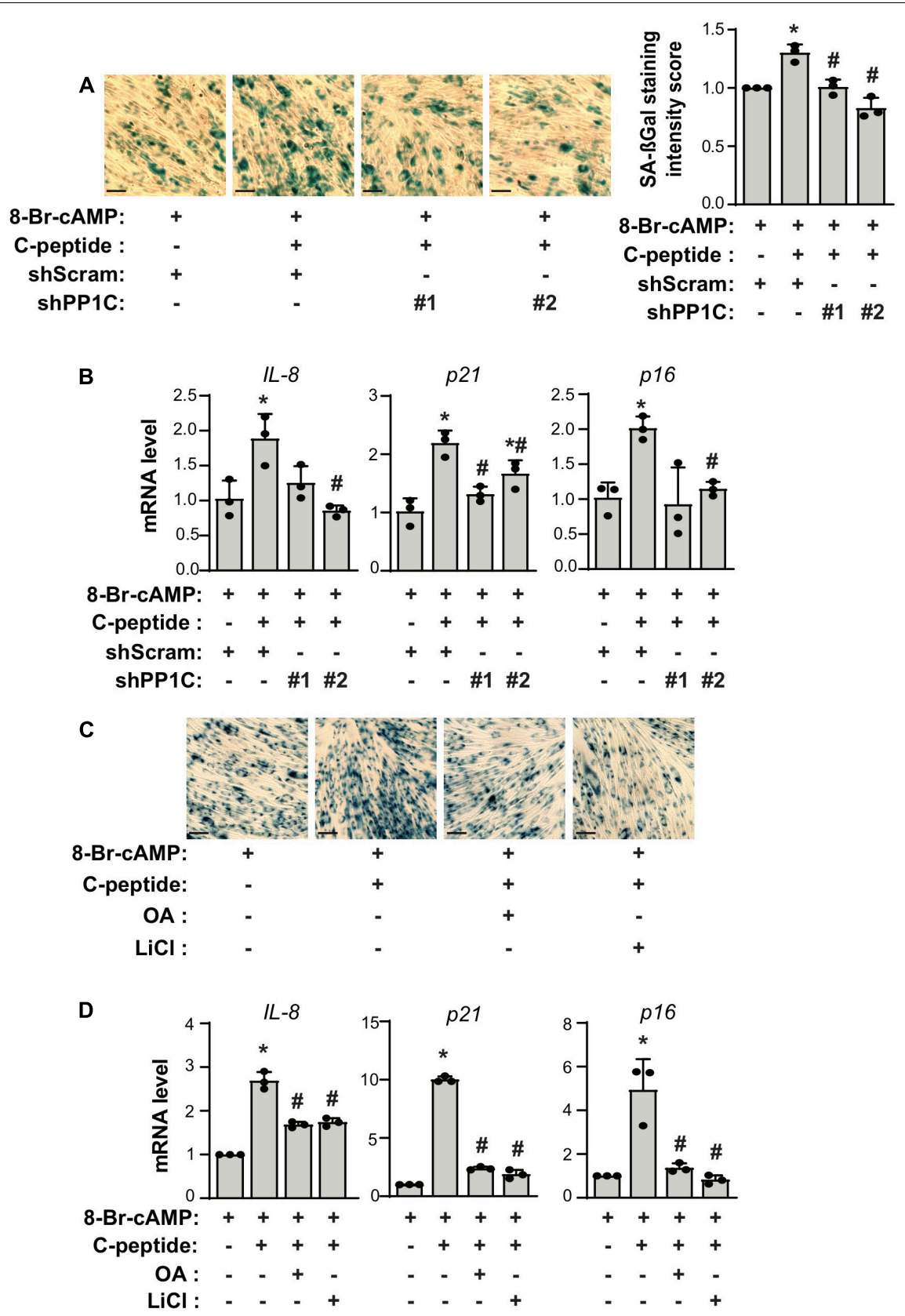

FIGURE 7 | C-peptide increases cellular senescence via PP1-GSK3 $\beta$. (A,B) Human eSCs were transduced with shScram and shPP1C, selected using $2 \mu \mathrm{M}$ puromycin for 5 days. (A) Cells were induced to differentiate with $0.5 \mathrm{mM} 8$-Br-cAMP in the presence or absence of $50 \mathrm{nM} \mathrm{C}$-peptide for 4 days. Cellular senescence was measured using a senescence-associated $\beta$-galactosidase (SA- $\beta G$ ) assay $(n=3)$. (B) Cells were differentiated as $(\mathbf{A})$ for 24 h. The lysates were subjected to qRT-PCR $(n=3)$. (C) Cells were pretreated with $10 \mathrm{nM}$ OA or $40 \mu \mathrm{M} \mathrm{LiCl}$ for $1 \mathrm{~h}$ and then induced to differentiate with $0.5 \mathrm{mM} 8$-Br-cAMP in the presence or absence of $50 \mathrm{nM} \mathrm{C-peptide} \mathrm{for} 4$ days. Cellular senescence was measured using SA- $\beta$ G assay $(n=3)$. (D) The cells were treated as described in (C) for $24 \mathrm{~h}$, followed by lysis, and the RNA was analyzed by qRT-PCR. ${ }^{\star} P<0.05$ vs. an undifferentiated control; ${ }^{*} P<0.05$ vs. a differentiated control. The cells were photographed by imager Z1 Zeiss microscope (X5), Scale bar = $100 \mu \mathrm{m}$. Human eSCs from two to four different people were used.

is regulated by several kinases, including $\mathrm{AKT}, \mathrm{PKA} / \mathrm{PKC}$, and p90RSK (Manning and Toker, 2017). Treatment with C-peptide reduced phosphorylation of GSK3 $\beta$ at Ser9 in undifferentiated human eSCs (Figure 5A) as well as in decidualized eSCs (Figure 5B). The protein level of $\beta$-catenin remained unchanged after stimulation with C-peptide (Figure 5A). Notably, C-peptide activated protein phosphatase activity (Figure 5C). Knockdown of PP1 C (catalytic subunit) with two independent shRNAs decreased C-peptide-induced protein phosphatase activity in human eSCs (Figure 5D), suggesting that protein phosphatase activity is primarily facilitated by PP1 activity in C-peptidestimulated human eSCs. Both PP1C knockdown (Figure 5E) and 

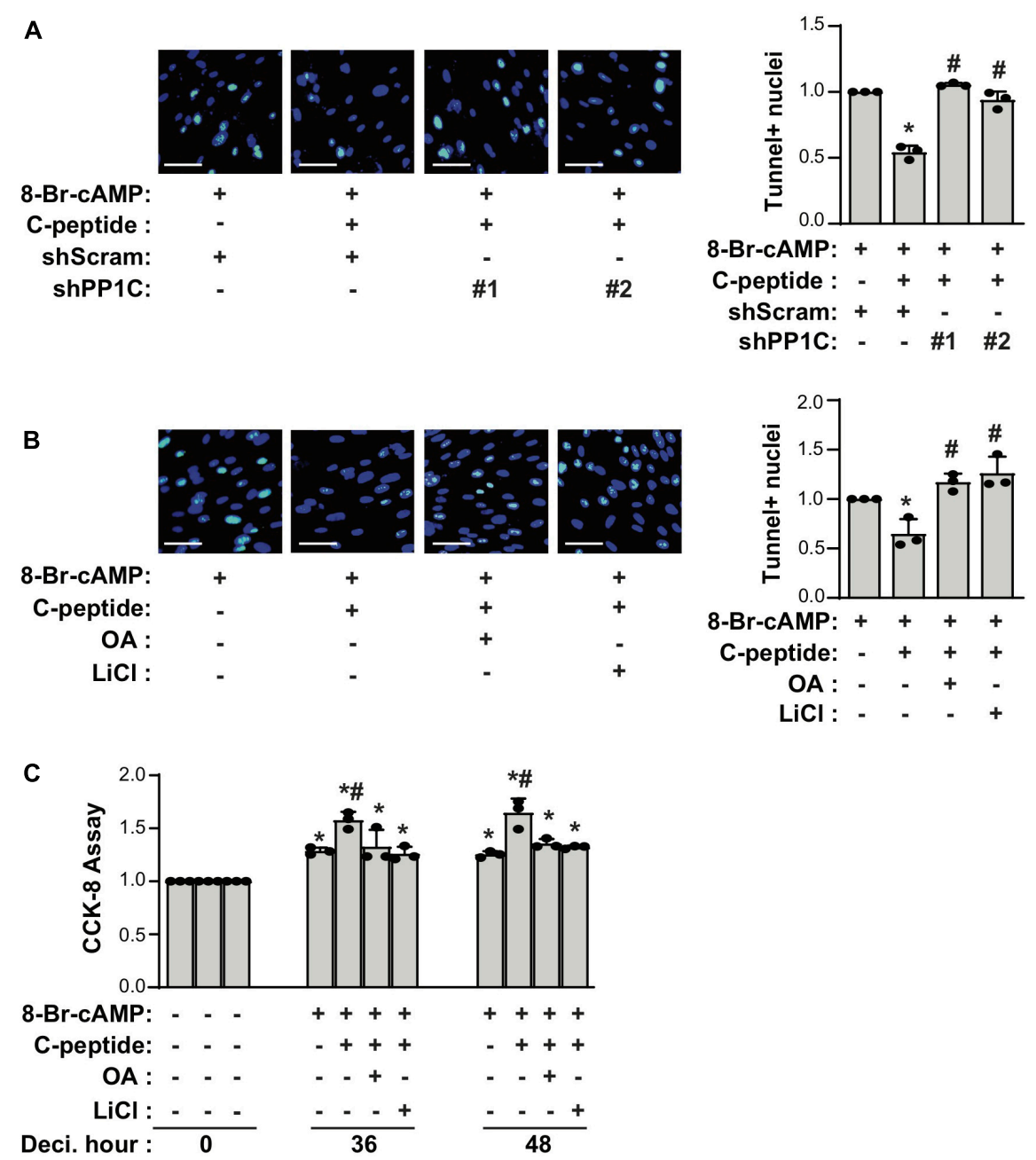

FIGURE 8 | C-peptide inhibits apoptosis in a PP1-GSK3 $\beta$-dependent manner. (A) Human eSCs were transduced with shScram and shPP1C, followed by selection using $2 \mu \mathrm{M}$ puromycin for 5 days. Cells were induced to differentiate with $0.5 \mathrm{mM} 8$-Br-cAMP in the presence or absence of $50 \mathrm{nM}$ C-peptide for 2 days. Cells were then subjected to TUNEL assay, and TUNEL+ nuclei were counted using Image $\mathrm{J}(n=3)$. (B) Cells were pretreated with $10 \mathrm{nM} \mathrm{OA}$ or $40 \mu \mathrm{M} \mathrm{LiCl}$ for $1 \mathrm{~h}$ and then induced to differentiate with $0.5 \mathrm{mM} 8$-Br-cAMP in the presence or absence of $50 \mathrm{nM}$ C-peptide for 2 days. Cells were subjected to TUNEL assay $(n=3)$. (C) Cells were pretreated with $10 \mathrm{nM} \mathrm{OA}$ or $40 \mu \mathrm{M} \mathrm{LiCl}$ for $1 \mathrm{~h}$ and then induced to differentiate with $0.5 \mathrm{mM} 8$-Br-cAMP in the presence or absence of $50 \mathrm{nM} \mathrm{C}$-peptide for the indicated times. The cells were lysed and subjected to CCK-8 assay $(n=3) .{ }^{*} P<0.05$ vs. an undifferentiated control; ${ }^{\#} P<0.05$ vs. a differentiated control. The cells were photographed using Olympus CKX53 microscope (X20). Scale bar $=50 \mu \mathrm{m}$. Human eSCs from two to four different people were used.

pretreatment with okadaic acid (OA), an inhibitor of PP1 (Yoon et al., 2005), for $1 \mathrm{~h}$ (Figure 5F) restored GSK3 $\beta$ phosphorylation in C-peptide-stimulated cells, implying the involvement of PP1 in the regulation of GSK3 $\beta$ phosphorylation. In addition, C-peptide induced PP1 inhibitor2 (I2) phosphorylation at Thr72 (Figure 5G), which induced the dissociation of I2 from PP1 and subsequent activation of PP1 (Monteserin-Garcia et al., 2013). In line with this result, GSK3 $\beta$ inhibition by $\mathrm{LiCl}$ abolished $\mathrm{C}$-peptide-induced protein phosphatase activity (Figure $5 \mathbf{H}$ ), suggesting that GSK $3 \beta$ activation is required for PP1 protein phosphatase activity via I2 phosphorylation. Additionally, C-peptide-induced reduction in GSK3 $\beta$ phosphorylation was abolished in both $\mathrm{OA}$ and LiCl-pretreated human eSCs during decidualization (Figure 6A). mRNA expression of decidualization markers, $P R L$ and IGFBP1, was restored by PP1C knockdown (Figure 6B), PP1 inhibition by OA, and GSK3 $\beta$ blockage by $\mathrm{LiCl}$ (Figure 6C). These results suggest that the antideciduogenic effect of $\mathrm{C}$-peptide is facilitated by a decrease in inhibitory GSK3 $\beta$ phosphorylation, which is achieved using a PP1-dependent mechanism.

\section{C-Peptide Increases Cellular Senescence and Decreases Apoptosis Using a GSK3 $\beta$-PP1-Dependent Mechanism}

If both PP1 and GSK3 $\beta$ are responsible for the antideciduogenic effect of C-peptide in human eSCs, one would expect that PP1 and GSK3 $\beta$ regulated cellular senescence and apoptosis during 8-Br-cAMP-induced decidualization. First, we assessed 


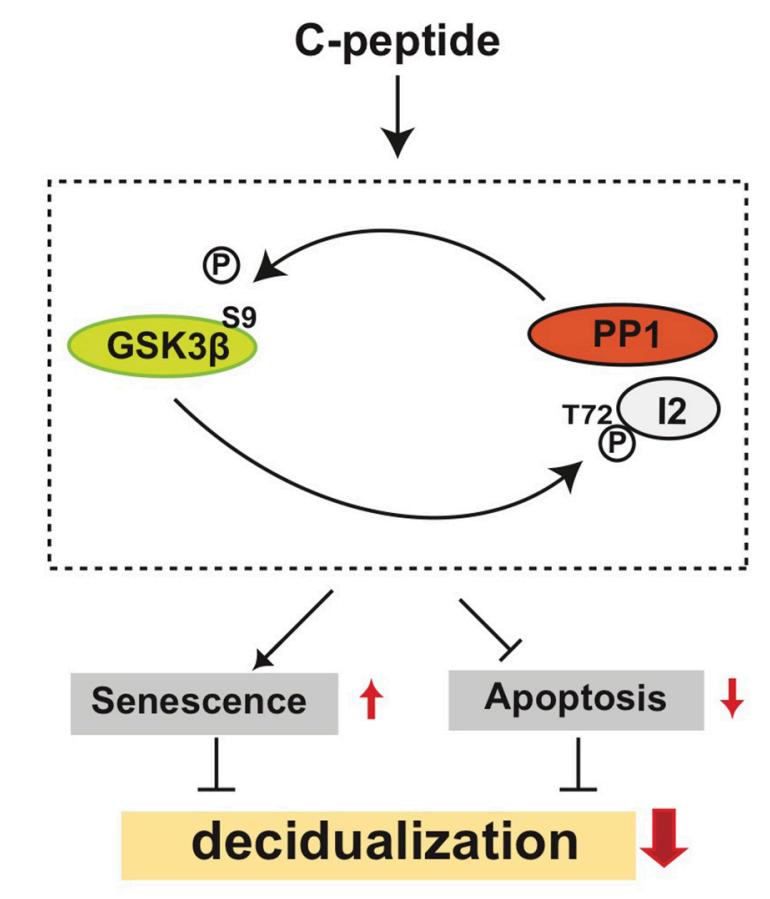

FIGURE 9 | A hypothetical model of the antideciduogenic effect of C-peptide. C-peptide activates PP1, which dephosphorylates GSK3 3 inhibitory phosphorylation at Ser 9. At the same time, active GSK3 $\beta$ phosphorylates 12 at Thr72, which might result in the dissociation of I2 from PP1. The cross-activation between PP1 and GSK3 $\beta$ increases cellular senescence and decreases apoptosis, leading to the inhibition of decidualization.

the effect of PP1C on cellular senescence in human eSCs. The depletion of PP1C using shRNA (Figures 7A,B) or inhibition of PP1 with OA pretreatment (Figures 7C,D) significantly reduced the number of $\mathrm{SA} \beta \mathrm{G}^{+}$eSCs and the mRNA expression of $I L$ $8, p 21$, and $p 16$ during 8-Br-cAMP-induced decidualization. In addition, pretreatment with $\mathrm{LiCl}$ significantly decreased $\mathrm{SA} \beta \mathrm{G}^{+}$eSCs and the mRNA expression of $I L-8, p 21$, and $p 16$ during 8-Br-cAMP-induced decidualization (Figures 7C,D). The number of TUNEL+ cells in C-peptide-treated PP1C knockdown cells was comparable to that in scramble-infected control cells (Figure 8A). In addition, the number of TUNEL+ cells was also elevated in $\mathrm{OA}$ or $\mathrm{LiCl}$-pretreated eSCs in the presence of C-peptide during decidualization (Figure 8B). Consistently, the number of decidualized cells that were pretreated with $\mathrm{OA}$ or $\mathrm{LiCl}$ remained unchanged as compared to the differentiated control in C-peptide-treated cells, as proved by the CCK- 8 assay (Figure 8C). These results suggest that $\mathrm{C}$-peptide plays a vital role in increasing cellular senescence and decreasing apoptosis in a GSK3 $\beta$ - and PP1-dependent manner.

\section{DISCUSSION}

C-peptide was initially considered an inert metabolic byproduct, but recently it has been shown to be a critical molecule for the regulation of various cellular and physiological conditions, especially those related to diabetes (Bhatt et al., 2014). This study demonstrates that C-peptide inhibits, but does not completely obstruct decidualization, which increases cellular senescence and decreases apoptosis in human eSCs via a GSK3 $\beta$ - and PP1-dependent mechanism (Figure 9). In addition, C-peptide activated PP1 activity using a GSK3 $\beta$-dependent mechanism, implying that these proteins create a positive feedback loop. The novel antideciduogenic effect of C-peptide supports the growing belief that C-peptide should be considered a critical factor in embryo implantation and pregnancy maintenance.

The level of C-peptide is normally $0.3-0.6 \mathrm{nM} / \mathrm{L}$ under fasting conditions, 1-3 nM/L under postprandial conditions (Leighton et al., 2017), and 0.77-1 nM/L in PCOS patients (Park et al., 2001; Ehrmann et al., 2004; de Medeiros et al., 2018); C-peptide has a half-life of 20-30 min (Jones and Hattersley, 2013). In the present study, we utilized $0.5-100 \mathrm{nM}$ C-peptide; in most cases $50 \mathrm{nM}$ was used. Treatment with physiological levels of C-peptide $(1 \mathrm{nM})$ for $10 \mathrm{~min}$ with dephosphorylated GSK3 $\beta$ (Figure 5A), suggested that the physiological concentration of C-peptide is effective enough to induce cellular signaling in human eSCs. In contrast, longer treatment with $1 \mathrm{nM} C$-peptide (more than $48 \mathrm{~h}$ ) is required to decrease the mRNA expression of $P R L$ (Supplementary Figure 1A). Hence, we assumed that a high concentration of $\mathrm{C}$-peptide is required for maintaining the effective level of C-peptide for 24-96 h (1-4 days) following the induction of decidualization. Importantly, to provide continuous supplementation with C-peptide over a long period, it should be administrated in vivo by using subcutaneously implanted osmotic pumps (Bhatt et al., 2013; Lim et al., 2015; Jeon et al., 2019). This ongoing supplementation is indispensable for testing the effect of C-peptide in decidualization in vivo. Along with the inhibitory role of C-peptide in decidualization in vitro, further investigation with osmotic pumps is required for determining the function of $\mathrm{C}$-peptide in decidualization in vivo.

Identification of the C-peptide receptor is necessary to decipher the mode of action and the biological role of C-peptide in diabetes-related complications. Previous studies have suggested that $\mathrm{C}$-peptide is associated with the activation of a G protein-coupled receptor (GPCR) with GPR146 identified as a potential C-peptide receptor following the investigation of 136 orphan GPCRs using ligand-receptor matching methodologies (Yosten et al., 2013). The knockdown of GPR146 inhibited $\mathrm{C}$-peptide-induced c-Fos expression in the gastric carcinoma cell line KATO III (Yosten et al., 2013). C-peptide was co-localized with GPR146 on the KATO III cell membrane, leading to the internalization of GPR146 (Yosten et al., 2013). However, a recent study did not support the finding that GPR146 is the C-peptide receptor (Lindfors et al., 2020). They utilized dynamic mass distribution, arrestin binding assays with GPR146 overexpressing cells, and cellular binding and internalization under a fluorescent microscope. None of these assays demonstrated reliable binding of GPR146 and C-peptide, or internalization of GPR146 in the presence of C-peptide. Since studies on C-peptide-related receptors in the endometrium have not been reported, further investigations need to be performed to examine the receptors and their C-peptide-induced antideciduogenic effects in the endometrium, possibly focusing on the highly expressed GPRs, 
including GPR139 or GPR161 (https://www.proteinatlas.org/ ENSG00000180269-GPR139/tissue).

In this study, we found that $\mathrm{C}$-peptide activated PP1, leading to dephosphorylation of GSK3 $\beta$ at Ser9 and activating GSK3 $\beta$ in human eSCs. Notably, PP1 was shown to be the primary effector of protein phosphatase activity in human eSCs (Figure 5). Spatial and temporal PP1 activity is regulated by the interactions between PP1 and the phosphatase-interacting proteins (PIP) (Pradhan et al., 2017). In the present study, GSK3 $\beta$ induced I2 phosphorylation at Thr72, which induced the dissociation of I2 from PP1 to activate PP1 activity (Monteserin-Garcia et al., 2013). Both knockdown and inhibition of PP1 restored GSK $3 \beta$ inhibitory phosphorylation, and pretreatment with $\mathrm{LiCl}$ also decreased C-peptide-induced protein phosphatase activity. GSK3 $\beta$, an isoform of GSK, functions as a critical regulator of cell growth and development (Souder and Anderson, 2019). The activity of GSK $3 \beta$ is regulated by its inhibitory phosphorylation and sequestration in the cytosolic complex by Wnt, and GSK3 $\beta$ inactivation promotes cellular proliferation and differentiation by regulating the phosphorylation of cyclin D1 or $\beta$-catenin (Rider et al., 2006). Thus, the cross-activation of PP1-GSK3 $\beta$ is essential to the antideciduogenic function of $\mathrm{C}$-peptide, although the primary effector between PP1 and GSK $3 \beta$ needs to be confirmed.

In addition, we found that GSK3 $\beta$ activity is associated with an increase in $\mathrm{SA} \mathrm{G}^{+}$cells and a decrease in apoptotic cells in C-peptide-treated decidual cells. GSK3 $\beta$ has been reported to translocate to the nucleus and interact with p53 in old, senescent WI-38 human fetal lung fibroblasts. In addition, treatment with lithium, a GSK blocker, reduced the levels of p53, p21, and $\mathrm{SA}_{\beta} \mathrm{G}^{+}$WI-38 cells (Zmijewski and Jope, 2004). Furthermore, we observed that $C$-peptide increased the number of $\mathrm{SA}_{\beta} \mathrm{G}^{+}$ eSCs but decreased that of apoptotic eSCs in a GSK3 $\beta$-PP1dependent manner. The interaction between cellular senescence and apoptosis depends on the cell type (Childs et al., 2014). Senescent cells affect the growth or apoptotic program of neighboring cells by secreting soluble factors known as SASP (Childs et al., 2014). Conversely, apoptosis resistance could induce cellular senescence; apoptotic stimuli such as UVB or high-dose $\mathrm{H}_{2} \mathrm{O}_{2}$ promote cellular senescence and cell survival by upregulating antiapoptotic Bcl-2 (Childs et al., 2014). Moreover, serum withdrawal leads to replicative cellular senescence together with anti-apoptotic signaling via an increased level of Bcl2 in human fibroblasts (Childs et al., 2014). Which signal between cellular senescence and apoptosis acts primarily in the stimulation of C-peptide needs to be further investigated.

The link between impaired decidualization of eSCs and the development of senescence has recently been investigated. An increase in p21 expression was accompanied by cellular senescence in both NEDD8 and exchange protein activated by cAMP2 (EPAC2)-calneticulin-inhibited decidualization (Kusama et al., 2014; Liao et al., 2015). In addition, there was a subpopulation of senescent decidual cells, resulting in the presence of various senescent characteristics (p53 stabilization, enhanced expression of CDK inhibitor p16, decreased expression of lamin B1, histone H3 trimethylation, cell size increase, and SA- $\beta$-Gal activity). The decidual cells became polarized to form a mature subpopulation of acutely senescent decidual cells, which were abolished by uterine natural killer ( $\mathrm{uNK}$ ) cells in an interleukin 15 (IL-15)-dependent manner (Ochiai et al., 2019). Furthermore, senescent decidual cells have been hypothesized to develop from these presenescent, undifferentiated populations, which exert a significant influence on the secretory profile of the cells during decidualization (Deryabin et al., 2020). Immune cells clear senescent decidual cells, decreasing the number of emerging progesterone-resistant secondary senescent decidual cells, blocking in recurrent pregnancy loss (Lucas et al., 2020). Whether C-peptide regulates the immune cell population, including uNK cells, during decidualization warrants further investigation.

Our study is the first to establish an antideciduogenic role for C-peptide in human eSCs (Figure 9). C-peptide also controls the activation of GSK3 $\beta$ and PP1, thereby modulating cellular senescence and apoptosis during decidualization. This study provides useful insights into the physiological role of C-peptide in hyperinsulinemia conditions and expands our understanding of the underlying mechanism of recurrent pregnancy loss in patients with diabetes and PCOS.

\section{DATA AVAILABILITY STATEMENT}

The original contributions presented in the study are included in the article/Supplementary Material, further inquiries can be directed to the corresponding author/s.

\section{ETHICS STATEMENT}

All experiments were performed in compliance with the relevant guidelines and regulations of Gachon University (GAIRB2018301). The patients/participants provided their written informed consent to participate in this study.

\section{AUTHOR CONTRIBUTIONS}

SAK and M-SY designed the study. SAK, H-JC, and M-OB performed the experiments. SJC provided human endometrium samples. SAK and M-SY wrote the original draft of the manuscript, and reviewed and edited the manuscript. All authors have read and approved the final manuscript.

\section{FUNDING}

This work was supported by a National Research Foundation of Korea (NRF) grant funded by the Korean Government (Ministry of Science and ICT; NRF-2018R1A2B6004513).

\section{SUPPLEMENTARY MATERIAL}

The Supplementary Material for this article can be found online at: https://www.frontiersin.org/articles/10.3389/fcell.2020. 609551/full\#supplementary-material 


\section{REFERENCES}

Baek, M. O., Ahn, C. B., Cho, H. J., Choi, J. Y., Son, K. H., and Yoon, M. S. (2019). Simulated microgravity inhibits C2C12 myogenesis via phospholipase D2-induced Akt/FOXO1 regulation. Sci. Rep. 9:14910. doi: 10.1038/s41598019-51410-7

Baek, M. O., Song, H. I., Han, J. S., and Yoon, M. S. (2018). Differential regulation of mTORC1 and mTORC2 is critical for 8-Br-cAMP-induced decidualization. Exp. Mol. Med. 50, 1-11. doi: 10.1038/s12276-018-0165-3

Beischer, W., Keller, L., Maas, M., Schiefer, E., and Pfeiffer, E. F. (1976). Human C-peptide part I: radioimmunoassay. Klinische Wochen Schrift 54, 709-715.

Bhatt, M. P., Lim, Y. C., and Ha, K. S. (2014). C-peptide replacement therapy as an emerging strategy for preventing diabetic vasculopathy. Cardiovasc. Res. 104, 234-244. doi: 10.1093/cvr/cvu211

Bhatt, M. P., Lim, Y.-C., Kim, Y.-M., and Ha, K.-S. (2013). C-peptide activates AMPK $\alpha$ and prevents ROS-mediated mitochondrial fission and endothelial apoptosis in diabetes. Diabetes 62, 3851-3862. doi: 10.2337/db13-0039

Brighton, P. J., Maruyama, Y., Fishwick, K., Vrljicak, P., Tewary, S., Fujihara, R., et al. (2017). Clearance of senescent decidual cells by uterine natural killer cells in cycling human endometrium. eLife 6:e31274. doi: 10.7554/eLife.31274

Chakraborty, P., Goswami, S. K., Rajani, S., Sharma, S., Kabir, S. N., Chakravarty, B., et al. (2013). Recurrent pregnancy loss in polycystic ovary syndrome: role of hyperhomocysteinemia and insulin resistance. PLoS One 8:e64446. doi: 10. 1371/journal.pone.0064446

Childs, B. G., Baker, D. J., Kirkland, J. L., Campisi, J., and van Deursen, J. M. (2014). Senescence and apoptosis: dueling or complementary cell fates? EMBO Rep. 15, 1139-1153. doi: 10.15252/embr.201439245

de Medeiros, S. F., Angelo, L. C. A., de Medeiros, M. A. S., Banhara, C. R., Barbosa, B. B., and Yamamoto, M. M. W. (2018). The role of c-peptide as marker of cardiometabolic risk in women with polycystic ovary syndrome: a controlled Study. J. Clin. Med. Res. 10, 260-267. doi: 10.14740/jocmr3325w

Deryabin, P., Griukova, A., Nikolsky, N., and Borodkina, A. (2020). The link between endometrial stromal cell senescence and decidualization in female fertility: the art of balance. Cell. Mol. Life Sci. 77, 1357-1370. doi: 10.1007/ s00018-019-03374-0

Dunn, C. L., Kelly, R. W., and Critchley, H. O. (2003). Decidualization of the human endometrial stromal cell: an enigmatic transformation. Reprod. Biomed. Online 7, 151-161. doi: 10.1016/s1472-6483(10)61745-2

Ehrmann, D. A., Breda, E., Corcoran, M. C., Cavaghan, M. K., Imperial, J., Toffolo, G., et al. (2004). Impaired beta-cell compensation to dexamethasone-induced hyperglycemia in women with polycystic ovary syndrome. Am. J. Physiol. Endocrinol. Metab. 287, E241-E246. doi: 10.1152/ajpendo.00475.2003

Francis, J., Rai, R., Sebire, N. J., El-Gaddal, S., Fernandes, M. S., Jindal, P., et al. (2006). Impaired expression of endometrial differentiation markers and complement regulatory proteins in patients with recurrent pregnancy loss associated with antiphospholipid syndrome. Mol. Hum. Reprod. 12, 435-442. doi: 10.1093/molehr/gal048

Gellersen, B., and Brosens, J. J. (2014). Cyclic decidualization of the human endometrium in reproductive health and failure. Endocr. Rev. 35, 851-905. doi: 10.1210/er.2014-1045

Hills, C. E., and Brunskill, N. J. (2009). Cellular and physiological effects of C-peptide. Clin. Sci. 116, 565-574. doi: 10.1042/CS20080441

Jeon, H.-Y., Lee, Y.-J., Kim, Y.-S., Kim, S.-Y., Han, E.-T., Park, W. S., et al. (2019). Proinsulin C-peptide prevents hyperglycemia-induced vascular leakage and metastasis of melanoma cells in the lungs of diabetic mice. FASEB J. 33, 750-762. doi: 10.1096/fj.201800723R

Jones, A. G., and Hattersley, A. T. (2013). The clinical utility of C-peptide measurement in the care of patients with diabetes. Diabet. Med. 30, 803-817. doi: 10.1111/dme.12159

Kien, C. L., Bunn, J. Y., Stevens, R., Bain, J., Ikayeva, O., Crain, K., et al. (2014). Dietary intake of palmitate and oleate has broad impact on systemic and tissue lipid profiles in humans. Am. J. Clin. Nutr. 99, 436-445. doi: 10.3945/ajcn.113. 070557

Kusama, K., Yoshie, M., Tamura, K., Nakayama, T., Nishi, H., Isaka, K., et al. (2014). The role of exchange protein directly activated by cyclic AMP 2mediated calreticulin expression in the decidualization of human endometrial stromal cells. Endocrinology 155, 240-248. doi: 10.1210/en.2013-1478
Leighton, E., Sainsbury, C. A., and Jones, G. C. (2017). A practical review of C-peptide testing in diabetes. Diabetes Ther. 8, 475-487. doi: 10.1007/s13300017-0265-4

Leno-Duran, E., Ruiz-Magana, M. J., Munoz-Fernandez, R., Requena, F., Olivares, E. G., and Ruiz-Ruiz, C. (2014). Human decidual stromal cells secrete soluble pro-apoptotic factors during decidualization in a cAMP-dependent manner. Hum. Reprod. 29, 2269-2277. doi: 10.1093/humrep/deu202

Liao, Y., Jiang, Y., He, H., Ni, H., Tu, Z., Zhang, S., et al. (2015). NEDD8mediated neddylation is required for human endometrial stromal proliferation and decidualization. Hum. Reprod. 30, 1665-1676. doi: 10.1093/humrep/ dev117

Lim, Y.-C., Bhatt, M. P., Kwon, M.-H., Park, D., Na, S., Kim, Y.-M., et al. (2015). Proinsulin C-peptide prevents impaired wound healing by activating angiogenesis in diabetes. J. Investig. Dermatol. 135, 269-278. doi: 10.1038/jid. 2014.285

Lindfors, L., Sundstrom, L., Froderberg Roth, L., Meuller, J., Andersson, S., and Kihlberg, J. (2020). Is GPR146 really the receptor for proinsulin C-peptide? Bioorg. Med. Chem. Lett. 30:127208. doi: 10.1016/j.bmcl.2020.127208

Lucas, E. S., Vrljicak, P., Muter, J., Diniz-da-Costa, M. M., Brighton, P. J., Kong, C. S., et al. (2020). Recurrent pregnancy loss is associated with a pro-senescent decidual response during the peri-implantation window. Commun. Biol. 3:37. doi: 10.1038/s42003-020-0763-1

Manning, B. D., and Toker, A. (2017). AKT/PKB signaling: navigating the network. Cell 169, 381-405. doi: 10.1016/j.cell.2017.04.001

McAvoy, T., and Nairn, A. C. (2010). Serine/threonine protein phosphatase assays. Curr. Protoc. Mol. Biol. 92, 18.18.1-18.18.11. doi: 10.1002/0471142727. mb1818s 92

Monteserin-Garcia, J., Al-Massadi, O., Seoane, L. M., Alvarez, C. V., Shan, B., Stalla, J., et al. (2013). Sirtl inhibits the transcription factor CREB to regulate pituitary growth hormone synthesis. FASEB J. 27, 1561-1571. doi: 10.1096/fj.12-22 0129

Munoz-Espin, D., Canamero, M., Maraver, A., Gomez-Lopez, G., Contreras, J., Murillo-Cuesta, S., et al. (2013). Programmed cell senescence during mammalian embryonic development. Cell 155, 1104-1118. doi: 10.1016/j.cell. 2013.10.019

Nawaz, F. H., and Rizvi, J. (2010). Continuation of metformin reduces early pregnancy loss in obese Pakistani women with polycystic ovarian syndrome. Gynecol. Obstet. Invest. 69, 184-189. doi: 10.1159/000268051

Ochiai, A., Kuroda, K., Ozaki, R., Ikemoto, Y., Murakami, K., Muter, J., et al. (2019). Resveratrol inhibits decidualization by accelerating downregulation of the CRABP2-RAR pathway in differentiating human endometrial stromal cells. Cell. Death Dis. 10:276. doi: 10.1038/s41419-019-1511-7

Okada, H., Tsuzuki, T., and Murata, H. (2018). Decidualization of the human endometrium. Reprod. Med. Biol. 17, 220-227. doi: 10.1002/rmb2.12088

Park, K. H., Kim, J. Y., Ahn, C. W., Song, Y. D., Lim, S. K., and Lee, H. C. (2001). Polycystic ovarian syndrome (PCOS) and insulin resistance. Int. J. Gynaecol. Obstet. 74, 261-267. doi: 10.1016/s0020-7292(01)00442-8

Poniedziałek-Czajkowska, E., Mierzyński, R., Słodzińska, M., Dłuski, D., and Leszczyńska-Gorzelak, B. (2018). Adipokines and C-peptide in overweight and obese pregnant women. Ginekol. Pol. 89, 442-448. doi: 10.5603/GP.a2018.0076

Pradhan, S., Khatlani, T., Nairn, A. C., and Vijayan, K. V. (2017). The heterotrimeric $G$ protein $G \beta(1)$ interacts with the catalytic subunit of protein phosphatase 1 and modulates $G$ protein-coupled receptor signaling in platelets. J. Biol. Chem. 292, 13133-13142. doi: 10.1074/jbc.M117.796656

Rhee, J. S., Saben, J. L., Mayer, A. L., Schulte, M. B., Asghar, Z., Stephens, C., et al. (2016). Diet-induced obesity impairs endometrial stromal cell decidualization: a potential role for impaired autophagy. Hum. Reprod. 31, 1315-1326. doi: 10.1093/humrep/dew048

Rider, V., Isuzugawa, K., Twarog, M., Jones, S., Cameron, B., Imakawa, K., et al. (2006). Progesterone initiates Wnt-beta-catenin signaling but estradiol is required for nuclear activation and synchronous proliferation of rat uterine stromal cells. J. Endocrinol. 191, 537-548. doi: 10.1677/joe.1.07030

Rigler, R., Pramanik, A., Jonasson, P., Kratz, G., Jansson, O. T., Nygren, P., et al. (1999). Specific binding of proinsulin C-peptide to human cell membranes. Proc. Natl. Acad. Sci. U.S.A. 96, 13318-13323. doi: 10.1073/pnas.96.23.13318

Son, K., You, J. S., Yoon, M. S., Dai, C., Kim, J. H., Khanna, N., et al. (2019). Nontranslational function of leucyl-tRNA synthetase regulates myogenic 
differentiation and skeletal muscle regeneration. J. Clin. Invest. 129, 2088-2093. doi: 10.1172/JCI122560

Souder, D. C., and Anderson, R. M. (2019). An expanding GSK3 network: implications for aging research. Geroscience 41, 369-382. doi: 10.1007/s11357019-00085-z

Ujvari, D., Jakson, I., Babayeva, S., Salamon, D., Rethi, B., Gidlof, S., et al. (2017). Dysregulation of in vitro decidualization of human endometrial stromal cells by insulin via transcriptional inhibition of forkhead box protein O1. PLoS One 12:e0171004. doi: 10.1371/journal.pone.0171004

Wahren, J., Ekberg, K., Johansson, J., Henriksson, M., Pramanik, A., Johansson, B. L., et al. (2000). Role of C-peptide in human physiology. Am. J. Physiol. Endocrinol. Metab. 278, E759-E768. doi: 10.1152/ajpendo.2000.278.5. E759

Walcher, D., Babiak, C., Poletek, P., Rosenkranz, S., Bach, H., Betz, S., et al. (2006). C-Peptide induces vascular smooth muscle cell proliferation: involvement of SRC-kinase, phosphatidylinositol 3-kinase, and extracellular signal-regulated kinase 1/2. Circ. Res. 99, 1181-1187. doi: 10.1161/01.RES.0000251231.169 93.88

Yoon, M.-S., Koo, J. B., Jeong, Y. G., Kim, Y. S., Lee, J. H., Yun, H. J., et al. (2007). Phospholipase D1 as a key enzyme for decidualization in human endometrial stromal cells1. Biol. Reprod. 76, 250-258. doi: 10.1095/biolreprod.106.056226

Yoon, S. Y., Choi, J. E., Huh, J. W., Hwang, O., Nam Hong, H., and Kim, D. (2005). Inactivation of GSK-3beta in okadaic acid-induced neurodegeneration: relevance to Alzheimer's disease. Neuroreport 16, 223-227. doi: 10.1097/ 00001756-200502280-00004
Yosten, G. L., Kolar, G. R., Redlinger, L. J., and Samson, W. K. (2013). Evidence for an interaction between proinsulin C-peptide and GPR146. J. Endocrinol. 218, B1-B8.

Zhang, F., Shi, J. J., Thakur, K., Hu, F., Zhang, J. G., and Wei, Z. J. (2017). Anticancerous potential of polysaccharide fractions extracted from peony seed dreg on various human cancer cell lines via cell cycle arrest and apoptosis. Front. Pharmacol. 8:102. doi: 10.3389/fphar.2017.00102

Zhou, J., Zhou, W., Kong, F., Xiao, X., Kuang, H., and Zhu, Y. (2017). microRNA34a overexpression inhibits cell migration and invasion via regulating SIRT1 in hepatocellular carcinoma. Oncol. Lett. 14, 6950-6954. doi: 10.3892/ol.2017. 7090

Zmijewski, J. W., and Jope, R. S. (2004). Nuclear accumulation of glycogen synthase kinase-3 during replicative senescence of human fibroblasts. Aging Cell 3, 309-317. doi: 10.1111/j.1474-9728.2004.00117.x

Conflict of Interest: The authors declare that the research was conducted in the absence of any commercial or financial relationships that could be construed as a potential conflict of interest.

Copyright (C) 2020 Khaliq, Baek, Cho, Chon and Yoon. This is an open-access article distributed under the terms of the Creative Commons Attribution License (CC BY). The use, distribution or reproduction in other forums is permitted, provided the original author(s) and the copyright owner(s) are credited and that the original publication in this journal is cited, in accordance with accepted academic practice. No use, distribution or reproduction is permitted which does not comply with these terms. 